\title{
Acute post-infectious cerebellitis
}

\author{
Cerebelite aguda pós-infecciosa \\ William Alves Martins ${ }^{1}$, Rafael do Amaral Cristovam ${ }^{1}$, André Palmini1,2
}

A 19-year-old woman presented with a one-week history of headache, vomiting and ataxia. A few days earlier, she had an upper airway infection. Brain MRI showed diffuse swelling and hyperintensities of the cerebellar hemispheres (Figure). Laboratory studies did not reveal any etiological factor. She was started on mannitol and dexamethasone, completely improving over the next days.
Acute cerebellitis is characterized by diffuse or focal cerebellar swelling ${ }^{1,2}$, sometimes compressing or even occluding the fourth ventricle ${ }^{3}$. Treatment relies on corticosteroids ${ }^{4}$. As it may be confused with infiltrative tumors $^{3}$, knowledge of this condition is important to avoid unnecessary procedures.
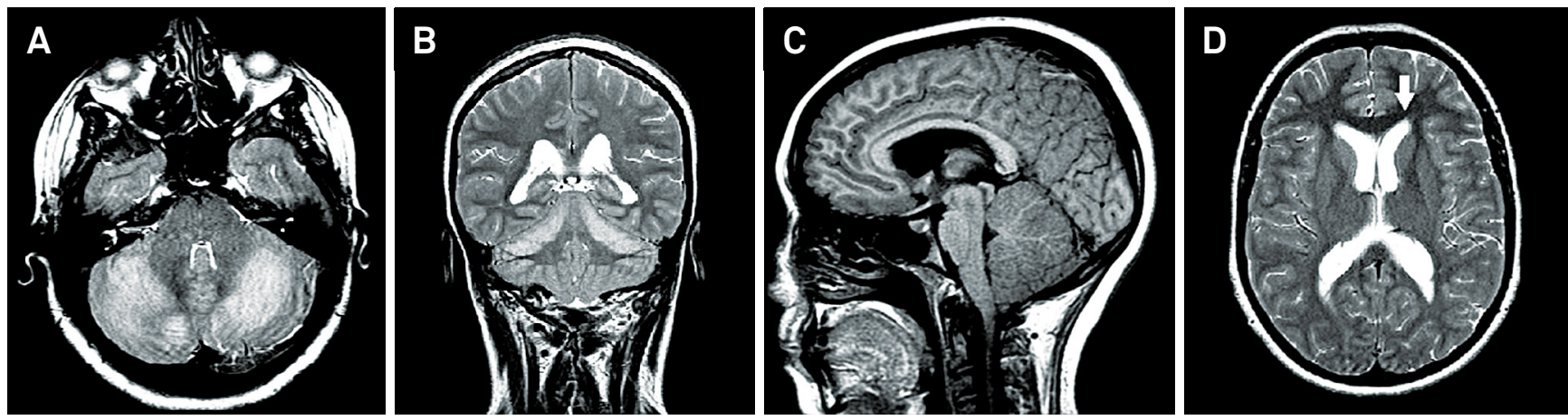

Figure. Brain magnetic resonance imaging at presentation. (A) Axial T2-weighted image shows increased signal intensity in both cerebellar hemispheres and compression of the $4^{\text {th }}$ ventricle; (B) Coronal T2-weighted image showing cerebellar cortex hyperintensities; (C) Sagittal T1-weighted image demonstrating partial compression of $4^{\text {th }}$ ventricle and brainstem; (D) Axial T2-weighted image shows enlargement of the lateral ventricles and subtle intersticial peri-ependimary edema (arrow).

\section{References}

1. Bakshi R, Bates VE, Kinkel PR, MechtleR LL, Kinkel WR. Magnetic resonance imaging findings in acute cerebellitis. Clin Imaging. 1998;22(2):79-85. doi:10.1016/S0899-7071(97)00093-4

2. Sawaishi Y, Takada G. Acute cerebellitis. Cerebellum. 2002;1(3):223-8. doi:10.1080/14734220260418457
3. Kamate M, Chetal V, Hattiholi V. Fulminant cerebellitis: a fatal clinically isolated syndrome. Pediatr Neurol. 2009;41(3):220-2. doi:10.1016/j.pediatrneurol.2009.03.018

4. Yis U, Kurul SH, Cakmakçi H, Dirik E. Acute cerebellitis with cerebellar swelling successfully treated with standard dexamethasone treatment. Cerebellum. 2008;7(3):430-2. doi:10.1007/s12311-008-0045-9

1Pontifícia Universidade Católica do Rio Grande do Sul, Hospital São Lucas, Departamento de Neurologia, Porto Alegre RS, Brazil;

${ }^{2}$ Pontifícia Universidade Católica do Rio Grande do Sul, Faculdade de Medicina, Departamento de Medicina Interna / Neurologia, Porto Alegre RS, Brazil. Correspondence: William Alves Martins; Serviço de Neurologia, Hospital São Lucas da PUCRS; Avenida Ipiranga, 6690; $90610-000$ Porto Alegre RS, Brasil; E-mail:walvesm.br@gmail.com

Conflict of interest: There is no conflict of interest to declare.

Disclosures: Dr. Palmini has received honoraria for talks and participation in advisory boards from Novartis, Abbott, Eli Lilly and Janssen-Cilag. Drs. Martin, Cristovam and have no disclosures relevant to this publication.

Received 09 April 2015; Received in final form 30 May 2015; Accepted 18 June 2015. 